\title{
Debris flow disaster in Larcha, upper Bhotekoshi Valley, central Nepal
}

\author{
Danda P Adhikari†* and Satoshi Koshimizu‡ \\ † JSPS Research fellow, Earth Science Division, Yamanashi Institute of Environmental Sciences, 5597-1, Kenmarubi, Kamiyoshida, \\ Fujiyoshida, Yamanashi 403-0005, JAPAN \\ Permanent Address: Department of Geology, Tri-Chandra Multiple Campus, Tribhuvan University, PO Box 13644, Kathmandu, \\ NEPAL \\ ¥ Earth Science Division, Yamanashi Institute of Environmental Sciences, 5597-1, Kenmarubi, Kamiyoshida, Fujiyoshida, \\ Yamanashi 403-0005, JAPAN
}

*To whom correspondence should be addressed.E-mail: adhikaridp@hotmail.com

In the Himalayas, damage, destruction, and casualties related to landslide and debris flow are common phenomena, especially during the monsoon period. This fact was tragically illustrated at 11:30 pm on 22 July 1996 when Larcha, situated at km-109 milestone of the Arniko Highway, upper Bhotekoshi Valley experienced an unprecedented debris flow down poured by the Bhairabkunda Stream (BKS). Geologically, Larcha is almost at the northern edge of the Lesser Himalaya close to the Main Central Thrust (MCT) zone in central Nepal. Out of the 22 business and residential houses located at the disaster site, 13 along the highway sides and 3 from the terrace were swept away, 2 were partially damaged (Figure 1a and b); and 54 residents on their beds were killed in a matter of a few minutes. The debris surge also washed out 5 water mills, one temple, $150 \mathrm{~m}$ of road stretch and a highway bridge over the BKS, and destroyed crops and agricultural lands. Apart from the loss of life and damage to the infrastructures and properties, human suffering was tremendously high and the mountain environment was deteriorated at an alarming rate. Despite the severity of the event, this area did not experience heavy rainfall for the past two weeks; but continual rainfall of small intensity had been observed from the beginning of July. This case study, in one hand, furnishes an example of how disastrous can be a small event at the base of steep mountain slope if settled underestimating the natural process, and on the other hand, it provides basis for questioning the widely held concept of debris flow can occur only during high intensity precipitation.

The Bhotekoshi valley is characterized by chronically unstable slopes composed of very thick unconsolidated soil cover. The BKS, one of the right tributaries of the Bhotekoshi River with an average slope of $30 \%$ drains a basin $\left(25.25 \mathrm{~km}^{2}\right)$ underlain by both the Lesser Himalayan and the Higher Himalayan rocks, allowing source rock composition to be the controlled variable to understand the source of the debris generation. The lower reaches of the basin is very steep as compared to the upper part, and in Larcha area the BKS follows the regional trend of the strike. The basin has either unstable dip slopes mantled by discontinuous thick surficial deposit or vertical cliff. The lower mountain slopes have extensive talus cones and relict colluvial veneers with deep erosional gullies and slump scars. Rock fall chutes are common along the wall of the cliff and bouldery loose sagging mass blanket the torrent embankment below bedrock cliff.

Bhairab Kunda Glacier Lake located at an altitude of 4467 $\mathrm{m}$ in the Higher Himalaya supplies head water for the $10 \mathrm{~km}$ long BKS. Glacier lakes in the Himalayas are retreating fast in alarming rates and there were several cases of Glacier Lake Outburst Flood (GLOF) in the second half of the past century in the territory of Nepal. As the main source of the stream is glacier lake, which, including most part of the catchment area, is generally invisible and inaccessible during monsoon period, media then linked the event to the GLOF. This study provided a basis for questioning the then widely held concept of GLOF.

Because no one observed the event, our knowledge of it is based on indirect evidence and inference together with survivors' account and our experience to the area. Monsoon rain contributed to incipient instabilities and the stream undercutting further enhanced the instabilities along the embankments. As a result, plane rock failure occurred on the phyllite beds at the notch of a $50 \mathrm{~m}$ high waterfall at about $400 \mathrm{~m}$ upstream from the bridge site; this in turn removed support for the overlying and adjacent soil mass. Soil sliding and slumping propagated rapidly up the slope so that a large volume of materials began to move almost simultaneously like a 'slopeclearing event'. Detached rock blocks blocked the stream flow for a short time and a large volume of debris was mobilized from the side masses. By any mechanism, eventually the dam breached the narrow outlet and the surge of debris overwhelmed the small settlement along the Arniko Highway (Figure 1a and b) and mixed into the Bhotekoshi River. According to the survivors' account, the Larcha area experienced a threatening noise from the bouncing of boulders and ground shaking as if it was stricken by a strong earthquake.

Material transformation into debris flow was promoted by the lack of sorting and the presence of silt and clay, both of which significantly lowered the soil permeability. Reduced permeability cause pore water to be trapped, increasing hydrostatic pressure, adding strength to the interstitial fluid phase, and decreasing shear strength of soil. Maximum flow depth was estimated from the elevation of mud lines on the valley wall that ranged from 7 $9 \mathrm{~m}$. Some of the largest blocks transported in the debris front measure 10x6.8x6.6 $\mathrm{m}^{3}, 10.5 \times 5.5 \times 3 \mathrm{~m}^{3}, 8.6 \times 6.7 \times 3.7 \mathrm{~m}^{3}, 8.5 \times 4.3 \times 2.5$ $\mathrm{m}^{3}$, and $7.5 \times 6.5 \times 5.7 \mathrm{~m}^{3}$. The debris deposited as a fan measuring $400 \mathrm{~m}$ long, $30-150 \mathrm{~m}$ wide and 2-7 $\mathrm{m}$ thick with an average slope of $10^{\circ}$.Total volume of the materials up to the high flood level was estimated to be $175,200 \mathrm{~m}^{3}$, and the actual volume deposited on the fan was about $106,800 \mathrm{~m}^{3}$ spreading over $26,000 \mathrm{~m}^{2}$ before channel erosion began.

Based on petrographic composition and size of individual fragment, the debris flow deposit was easily discernible into three segments with a blocky front. The materials were predominantly of the Lesser Himalayan origin, ruling out the possibility of GLOF although some Higher Himalayan materials were observed as reworked material, transported not from above the middle reaches of the catchment. Tree ring counting on trunks deposited on the debris fan yielded ages from 60 to 65 years, which probably indicates the recurrence interval of debris flow of the equal or smaller magnitude. 


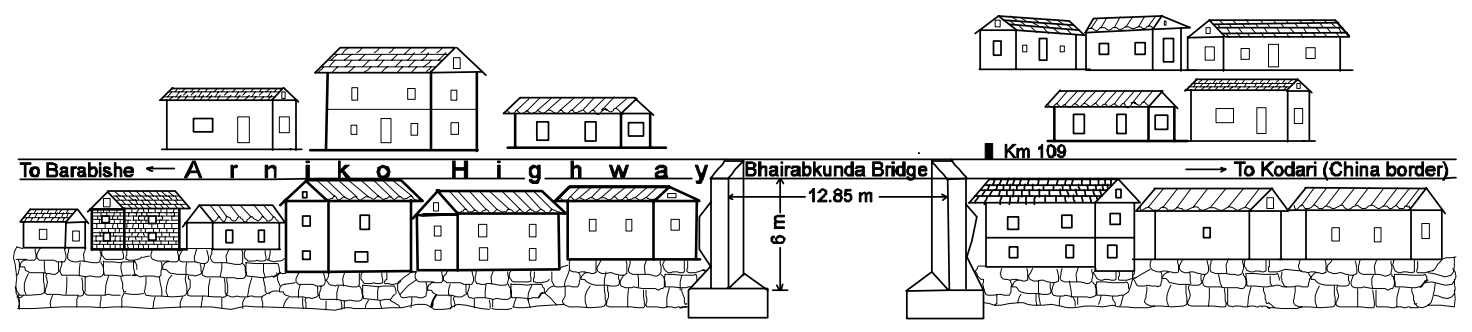

(a)

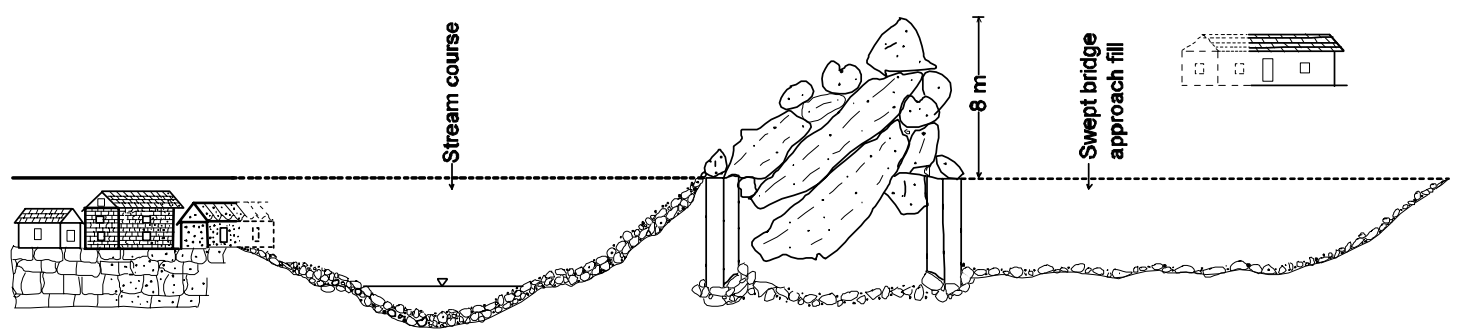

(b)

FIGURE 1. Schematic map of the settlement along the highway sides at Larcha: (a) before (based on old photographs and field knowledge) and (b) after the disaster 